\title{
Sleep, circadian rhythms, and the pathogenesis of Alzheimer Disease
}

\author{
Erik S Musiek, David D Xiong and David M Holtzman
}

Disturbances in the sleep-wake cycle and circadian rhythms are common symptoms of Alzheimer Disease (AD), and they have generally been considered as late consequences of the neurodegenerative processes. Recent evidence demonstrates that sleep-wake and circadian disruption often occur early in the course of the disease and may even precede the development of cognitive symptoms. Furthermore, the sleep-wake cycle appears to regulate levels of the pathogenic amyloid-beta peptide in the brain, and manipulating sleep can influence AD-related pathology in mouse models via multiple mechanisms. Finally, the circadian clock system, which controls the sleep-wake cycle and other diurnal oscillations in mice and humans, may also have a role in the neurodegenerative process. In this review, we examine the current literature related to the mechanisms by which sleep and circadian rhythms might impact AD pathogenesis, and we discuss potential therapeutic strategies targeting these systems for the prevention of AD.

Experimental \& Molecular Medicine (2015) 47, e148; doi:10.1038/emm.2014.121; published online 13 March 2015

\section{INTRODUCTION}

Though sleep consumes a considerable portion of our lives, its biological functions and biochemical implications are still poorly understood. Efficient and effective sleep is more than just a luxury; it is critical for the proper function of many organ systems, particularly the brain. The sleep-wake cycle is the most obvious example of a circadian process, as it occurs with a consistent 24-h rhythm and can be shifted according to environmental cues. The body's circadian clock system maintains these 24-h rhythms in physiological functions, including the sleep-wake cycle, and synchronizes them to the light-dark cycle. Disturbances of both sleep and the underlying circadian rhythms have long been associated with many neurological and psychiatric diseases, including Alzheimer Disease (AD). AD, a devastating age-related neurodegenerative disease characterized by aggregation and accumulation of amyloid- $\beta$ (A $\beta)$ and tau proteins, is the most common cause of dementia in older people worldwide. $\mathrm{AD}$ patients often exhibit disrupted day-night activity patterns and fragmented or mistimed sleep, which can cause great morbidity and is a major cause of institutionalization. Although these sleep and circadian abnormalities were once dismissed as consequences of the disease process, accumulating evidence suggests that sleep and circadian disturbances likely occur very early in the disease process and may contribute to the pathogenesis of $\mathrm{AD}$. Thus, the possibility exist that treating the sleep-wake and circadian dysfunction early, even prior to the development of $\mathrm{AD}$ pathology, might prevent or slow the development of subsequent pathology and later dementia. In Part I of this review, we will discuss the considerable evidence implicating sleep-wake disturbances in the development of A $\beta$ pathology and pathogenesis of AD. In Part II, we will discuss the circadian clock and its function in $\mathrm{AD}$ and then postulate on the possible mechanisms by which circadian clock dysfunction could also contribute to $\mathrm{AD}$. Finally, we will conclude with a brief discussion of the therapeutic implications of these findings.

\section{PART I: THE SLEEP-WAKE CYCLE AS A MODULATOR OF AD PATHOGENESIS}

Sleep disturbances are a common feature of $\mathrm{AD}$ and are observed in mouse $\mathrm{AD}$ models

Disorders of the sleep-wake cycle are a common and debilitating symptom of $\mathrm{AD}$. Sleep-wake disruption tends to occur in the moderate stages of the disease and can be multifaceted. The details of sleep disturbances in $\mathrm{AD}$ has been extensively reviewed elsewhere and is beyond the scope of this review. ${ }^{1,2}$ Briefly, $\mathrm{AD}$ patients exhibit disturbances in the timing and duration of the sleep cycle, primarily manifested as increased

Department of Neurology, Hope Center for Neurological Disorders Research \& Knight Alzheimer's Disease Research Center, Washington University School of Medicine, Saint Louis, MO, USA

Correspondence: Dr DM Holtzman, Department of Neurology, Washington University School of Medicine, Box 8111, 425S. Euclid Avenue, St Louis, MO 63110, USA. 
wakefulness at night (due to increased sleep latency and increased nocturnal awakenings) and increased sleep during the day, which can progress to a loss of day-night variation. ${ }^{3}$ In terms of sleep architecture, the duration of rapid eye movement (REM) sleep bouts is decreased in AD patients compared with age-matched controls, leading to a cumulative lack of REM sleep. ${ }^{4,5}$ Slow-wave sleep is also diminished in $\mathrm{AD}^{6,7}$ These changes can occur very early in the course of the disease. Several studies in transgenic mice demonstrate that amyloid deposition in the brain (and in some cases tau aggregation) leads to the disruption of normal sleep architecture, an effect that often precedes the appearance of amyloid plaques. Abnormalities in mice include a loss of robust day-night oscillation in brain lactate, ${ }^{8}$ phase delay, ${ }^{9}$ altered nocturnal activity level, ${ }^{10}$ and decreased non-REM sleep. ${ }^{1-13}$ In some cases, sleep abnormalities were reversed by $\mathrm{A} \beta$ immunotherapy, demonstrating a causative role for $A \beta .^{8,13}$ Thus, $A \beta$ causes sleep disturbances in mice that recapitulate some aspects of human $\mathrm{AD}$.

\section{Sleep disturbances may predict dementia and $\mathrm{A} \beta$ pathology} Recently, accumulating evidence has suggested that sleep disturbances may be early indicators of dementia and $A \beta$ pathology and may actually precede the onset of cognitive symptoms in AD. Self-reported sleep problems, as assessed by composite surveys of sleep-related symptoms, have been associated with an increased future risk of developing dementia within 1-9 years. $^{15-17}$ Objective sleep-wake data can be obtained using actigraphy, a method in which research subjects wear a small sensor that monitors movement. Although actigraphy measures behavioral activity, it has been shown to be a good surrogate marker for sleep when compared with electroencephalogram (EEG) based sleep studies. ${ }^{18,19}$ Fragmentation of sleep, which can be quantified using actigraphic data to analyze the frequency and duration of runs of uninterrupted rest during the night, may be an indicator or arbiter of cognitive impairment. ${ }^{20,21}$ Rest fragmentation at night increases with age and is associated with a 1.5 -fold increased risk of developing dementia in the ensuing 6-year follow-up period. ${ }^{21}$ In these studies, total rest time also decreased with age but was not associated with cognitive decline, suggesting that restactivity fragmentation has a more substantial impact on cognition. Accordingly, a prospective study showed that increased rest fragmentation at night appeared to exacerbate the effects of apolipoprotein E4 on dementia risk, amyloid plaque burden, and tau pathology. ${ }^{22}$ These studies suggest that alterations in the rest-activity pattern, particularly fragmentation of nighttime rest (a representation of poor sleep consolidation) might portend future development of dementia or even cerebral amyloid-beta (A $\beta)$ deposition. Thus, several studies have examined the relationship between sleep quality and $\mathrm{A} \beta$ pathology in cognitively normal older adults. Using actigraphy to assess sleep parameters, Ju et al. ${ }^{23}$ found that cognitively normal adults with cerebral $A \beta$ deposition on Pittsburgh Compound B (PiB) amyloid positron emission tomography (PET) (PiB) imaging were more likely to nap frequently and had significantly worse sleep efficiency than those without PiB-positive plaques. Subsequently, Spira et al. ${ }^{24}$ found that cognitively normal older adults who self-report poor sleep were more likely to have $A \beta$ plaque pathology in the precuneus, as also assessed by PiB PET imaging. In total, these studies suggest that presymptomatic amyloid deposition affects sleep and suggest that specific alterations in sleep or activity parameters might be an early biomarker of impending $\mathrm{AD}$. However, the effect sizes observed in these studies were small, illustrating that sleep alterations in preclinical $\mathrm{AD}$ are subtle. The existing literature also generally relies on actigraphy, which shows high correlation with EEG-based sleep studies, but does not provide detailed information about sleep stage or quantitative sleep-EEG data. Future studies using EEG-based sleep analysis are likely to provide deeper insights into the relationship between sleep and $A \beta$ pathology and other aspects of $\mathrm{AD}$ pathogenesis.

\section{Control of A $\beta$ levels by the sleep-wake cycle}

These studies on sleep and $\mathrm{AD}$ raise the possibility that altering sleep quality might impact $A \beta$ deposition. In support of this hypothesis, considerable evidence has emerged linking the sleep-wake cycle with $A \beta$ regulation in the brains of mice and humans. Using in vivo cerebral microdialysis, a method in which brain interstitial fluid (ISF) from brain regions such as the hippocampus can be sampled around the clock in awake, freely moving mice and assayed for $A \beta$, Kang et al. ${ }^{25}$ revealed that ISF A $\beta$ levels demonstrate a pronounced diurnal rhythm. When mice were kept in standard $12 \mathrm{~h}: 12 \mathrm{~h}$ light:dark conditions, levels of $A \beta$ were highest during the dark phase (when mice tend to be awake) and lowest during the light phase (when mice tend to be asleep). ISF $A \beta$ correlated closely with total minutes awake, and the usual dip in $A \beta$ levels at the onset of the light phase could be delayed if the mice were prevented from sleeping. Experiments in humans employing lumbar catheters to collect cerebrospinal fluid (CSF) around the clock revealed similar diurnal oscillations in CSF A $\beta$ levels as were observed in the ISF of mice, although the phase was delayed by $\sim 6 \mathrm{~h}$, presumably because of the transit time of $A \beta$ from the ISF to the lumbar CSF compartment several feet away. ${ }^{25,26}$ Thus, $A \beta$ levels in the brain appear to be closely linked to the sleep-wake cycle, both in mice and humans.

The mechanisms that mediate the diurnal oscillation in $A \beta$ are of critical importance, and they are still under investigation. One hypothesis is that $\mathrm{A} \beta$ oscillates as a result of similar oscillations in neuronal activity. ISF $A \beta$ levels are known to be regulated by neuronal activity, ${ }^{27-29}$ suggesting that increased neuronal activity during the wake phase might mediate the diurnal increase in $A \beta$. Slow wave sleep is associated with a period of neuronal hyperpolarization and diminished neuronal firing and might thus be expected to be associated with less $A \beta$ production. ${ }^{30}$ Loss of slow wave sleep, as seen in $\mathrm{AD}$ or sleep deprivation protocols, ${ }^{6}$ would be expected to result in higher cumulative levels of neuronal activity and greater $A \beta$ production. Accordingly, Roh et al. ${ }^{8}$ demonstrated that lactate, a marker of neuronal activity, ${ }^{29}$ also exhibited diurnal 
oscillation in the ISF in phase with $A \beta$. As plaque pathology advanced, the diurnal oscillations in both lactate and $A \beta$ became damped, but they were restored when plaques were eliminated following $A \beta$ immunotherapy. ${ }^{8}$ In humans with autosomal dominant $\mathrm{AD}$, oscillations in CSF $\mathrm{A} \beta$ also declined as amyloid plaque pathology became evident (as quantified by PiB PET imaging). This study clearly demonstrates the bidirectional relationship between $A \beta$ and sleep and supports the neuronal activity hypothesis. It also demonstrates that accumulating $A \beta$ pathology can mitigate diurnal oscillations in $\mathrm{A} \beta$ and disrupt the sleep-wake cycle.

While sleep might limit $A \beta$ production by tempering neuronal activity, it may also regulate the clearance of $A \beta$ from the brain. Xie et al. ${ }^{31}$ reported that sleep induces significant increases in the volume of extracellular fluid in the brain and enhances the convective bulk flow of metabolites and proteins out of the brain via the 'glymphatic' system, or the brain's form of lymphatic flow, which is controlled by glia. The clearance of exogenously injected $A \beta$ was significantly faster in sleeping mice than waking ones, suggesting that sleep might regulate extracellular $A \beta$ levels by enhancing the removal of $A \beta$ via glymphatic flow. Although this has not been demonstrated for endogenously derived $A \beta$, these sleep-related fluxes in bulk flow could also explain diurnal variation in the concentration of other proteins and metabolites, including lactate. Further investigation into these and other mechanisms to explain the diurnal oscillation of $A \beta$ is underway.

\section{Sleep deprivation exacerbates $A \beta$ pathology}

A clear implication of this relationship between the sleep-wake cycle and $A \beta$ levels is that altering sleep might also modulate $\mathrm{A} \beta$ pathology and potentially AD pathogenesis. Kang et al. ${ }^{25}$ found that forced sleep deprivation caused a striking increase in the $\mathrm{A} \beta$ plaque burden in transgenic mice that express $\mathrm{AD}$ associated mutant forms of human amyloid precursor protein (APP) and presenilin-1 (PS1) and develop A $\beta$ plaques with age. Conversely, treatment with the orexin antagonist almorexant, which increased sleep, decreased plaque burden. A subsequent study using mice that express human APP, PS1, and human Tau transgenes also demonstrated an increase in cortical $A \beta$ plaque burden following chronic sleep deprivation..$^{32}$ Although both studies showed an increase in $A \beta$ pathology with sleep deprivation, they differ on the role of stress-related glucocorticoids in the process. As stress is known to increase the $A \beta$ plaque burden in transgenic mice in a glucocorticoiddependent manner ${ }^{33-35}$ Rothman et al. ${ }^{32}$ reported a two-fold increase in glucocorticoid levels in sleep-deprived mice that correlated with plaque burden and suggested that glucocorticoids have a key role in this model. Kang et al. ${ }^{25}$ demonstrated that ISF A $\beta$ diurnal oscillations can occur in the presence of a corticotrophin releasing hormone antagonist, suggesting that glucocorticoids are not critical to $A \beta$ oscillations, though they did not directly address the role of glucocorticoids in their sleep deprivation experiments. It is likely that the sleep restriction paradigm and the mouse model used can play a major role in dictating how important glucocorticoids are in sleep deprivation-induced $A \beta$ deposition, as the mouse model employed by Rothman et al. ${ }^{36}$ was very sensitive to psychological stress. Regardless of the role of glucocorticoids, a human study employing CSF collection via a lumbar catheter in healthy volunteers showed that the CSF A $\beta$ level declines after a night of sleep, but this sleep-induced decline is prevented by sleep deprivation, resulting in a higher morning CSF $A \beta$ level. ${ }^{37}$ Thus, sleep deprivation appears to exacerbate $A \beta$ pathology in mice, and early data suggest that it might do the same in humans.

Sleep deprivation mediates $\mathrm{A} \beta$-independent neuronal injury Aside from alterations in $A \beta$, several studies have demonstrated that sleep deprivation can exacerbate neuronal injury via several mechanisms. For example, sleep deprivation can induce tau phosphorylation, synaptic injury, and impaired learning and memory in mice expressing mutant human tau, APP, and PS1 transgenes. ${ }^{32,38}$ In healthy human volunteers, a night of sleep deprivation led to a $20 \%$ increase in CSF levels of neuronspecific enolase and SB-100, two markers of neuronal injury, suggesting that even instances of acute sleep deprivation may cause neuronal injury. ${ }^{39}$ Sleep deprivation has also been shown to cause mitochondrial oxidative stress in wake-promoting neurons of the locus ceruleus, and, if prolonged, it can overwhelm the protective SirT3 signaling and cause the death of these neurons. ${ }^{40} \mathrm{As} \mathrm{AD}$ is generally considered a disease of protein aggregation, it is notable that sleep deprivation induces endoplasmic reticulum stress and activates the protective unfolded protein response, a response that wanes with age. ${ }^{41,42}$ Thus, sleep deprivation may compromise proteostasis in the aging brain, which could contribute to aggregation of $\mathrm{A} \beta$, tau or other proteins associated with neurodegeneration.

\section{Summary, part I}

Recent evidence in mice and humans is consistent with the concept that sleep disturbances are not only a consequence of the disease process in $\mathrm{AD}$ but might also precede symptom onset and may drive disease pathology (Figure 1). A $\beta$ levels in ISF and CSF exhibit diurnal oscillation that appears to be linked to the sleep-wake cycle and may be mediated by alterations in neuronal activity and/or bulk protein clearance by the glymphatic system. Sleep deprivation exacerbates $A \beta$ plaque pathology while enhancing sleep by inhibiting orexin signaling attenuates plaque accumulation. Finally, sleep deprivation exerts a variety $\mathrm{A} \beta$-independent effects in the brain that could exacerbate neurodegeneration. Because relatively small alterations in $A \beta$ levels can translate into considerable changes in plaque pathology over a long timeframe, ${ }^{43}$ chronic mild sleep disturbances throughout life might conceivably facilitate $A \beta$ deposition, setting in motion a feed-forward cycle in which $\mathrm{A} \beta$ pathology in turn impairs the sleep wake cycle. Poor sleep could also promote tau phosphorylation and neuronal injury that exacerbate $A \beta$-induced damage, leading to AD. Further research is needed to elucidate the molecular mechanisms that mediate the effects of sleep on $\mathrm{A} \beta$ and other neurodegenerative pathways, to determine the role of sleep in the genesis of $\mathrm{AD}$ in 


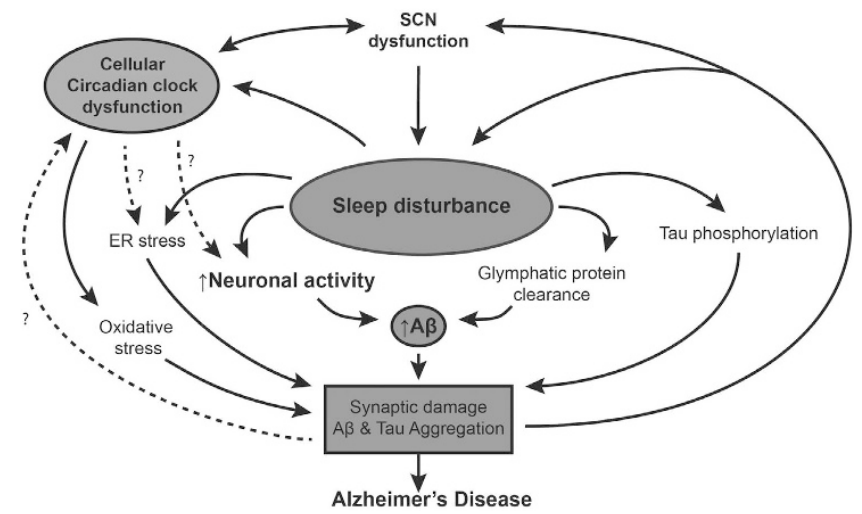

Figure 1 Proposed mechanisms linking sleep deprivation, circadian dysfunction, and AD. Dotted arrows represent hypothetical links.

humans, and to evaluate sleep parameters as therapeutic and diagnostic targets in $\mathrm{AD}$.

\section{PART II: CIRCADIAN DYSFUNCTION IN AD PATHOGENESIS}

Although accumulating evidence points to a strong relationship between the sleep-wake cycle and $\mathrm{AD}$ pathogenesis, it is important to consider the potential role of the circadian system in mediating some of the observed effects. In the next section, we will discuss how the circadian clock system regulates the sleep-wake cycle and many other aspects of physiology. Although the circadian clock and the sleep-wake cycle are intimately linked, the circadian system is an independent entity with unique therapeutic targets and considerations.

\section{Circadian rhythms are critical to human health}

Circadian rhythms, defined as oscillations with a period of $24 \mathrm{~h}$, are a fundamental component of mammalian physiology. Nearly all terrestrial organisms have circadian clock systems that serve to coordinate physiology with external cues such as the light-dark cycle. The circadian oscillation of the sleep-wake cycle is just one of many circadian processes in the body, and it is directly controlled by the circadian clock in mice and humans. Systemic circadian rhythms, such as those observed in the sleep-wake cycle, hormone secretion, and blood pressure, are controlled by the hypothalamic suprachiasmatic nucleus (SCN). The SCN signals via multiple mechanisms, including the autonomic nervous and hormone release, to synchronize cell-autonomous peripheral clocks throughout the body. The SCN controls circadian secretion of melatonin, the 'dark' hormone which promotes sleep onset, and SCN lesions lead to loss of circadian rhythms and an arrhythmic sleep-wake cycle in mice. ${ }^{44}$

Circadian rhythms in the SCN and in most cells throughout the body are maintained by a core cellular clock transcriptional machinery consisting of the bHLH/PAS transcription factors BMAL1 and CLOCK, which heterodimerize and drive transcription of many genes, including their own negative feedback repressors (PERIOD (Per) and CRYPTOCHROME (Cry) genes), which repress BMAL1/CLOCK- mediated transcription. ${ }^{45}$ BMAL1/CLOCK-mediated transcription is referred to as the 'positive limb' of the circadian clock, while the transcriptional suppressor proteins (Per1-3, Cry1-2) are termed the 'negative limb'. This core clock machinery is found not only in the SCN but also in almost all cells in the body, including neurons and astrocytes, ${ }^{46,47}$ and has been estimated to mediate the circadian transcription of $10-20 \%$ of all transcripts in a tissue-specific manner. ${ }^{45,48}$ The SCN serves as the master body clock, which synchronizes these peripheral oscillators into coherent whole-organism rhythms that are in synch with external light-dark cues. Importantly, wholeorganism circadian rhythms and cell-autonomous circadian oscillations are dissociable, as cells removed from an organism continue to oscillate in culture without SCN input and local deletion of clock genes can result in an arrhythmic organ or cell population within a normally rhythmic animal. Likewise, SCN lesions disrupt the synchronization of whole body rhythms but do not prevent the cellular clock from continuing to function in a given cell. ${ }^{49}$

The circadian clock serves as a master integrator of cellular metabolism in peripheral tissue, and circadian dysfunction has been implicated in the pathogenesis of aging and several disease states, including atherosclerosis, diabetes, and cancer. ${ }^{50-52}$ Accordingly, epidemiological evidence shows that humans with disturbed circadian rhythms because of shift work, jetlag, sleep disorder, or aging have an increased risk of metabolic syndrome, coronary disease, cancer, and other chronic diseases. ${ }^{53}$

\section{Interplay between sleep-wake cycle and circadian rhythms} The sleep-wake cycle and circadian rhythms are often referred to interchangeably, and many studies examining parameters such as actigraphy do not distinguish between them. Sleep is clearly regulated by the circadian clock, as human sleep patterns follow clear circadian patterns, and deletion of the master clock gene Bmall abrogates all circadian function ${ }^{54}$ leading to a total loss of day-night rhythmicity of sleep..$^{55}$ However, the timing and duration of sleep are also controlled by other factors, such as sleep pressure and arousal. Sleep deprivation can alter the expression of clock genes and the DNA binding patterns of BMAL1/CLOCK heterodimers, thus altering clock function..$^{56}$ Moreover, efforts to study sleep and circadian phenomena are often muddled because interventions that disrupt rhythms (such as shifting the light: dark cycle or genetic deletion of clock genes) also disrupt sleep. Thus, the impact of such interventions on both sleep and circadian endpoints should be considered.

\section{Circadian dysfunction is a common symptom of Alzheimer disease}

Behavioral circadian rhythms decline in aged mice and humans, ${ }^{57,58}$ and dysregulation of systemic circadian rhythms, such as those seen in sleep-wake cycle, activity, and melatonin secretion, is a common symptom of $\mathrm{AD}$ dementia. ${ }^{3,58-62}$ Mouse models of $\mathrm{AD}$ also show disintegration of circadian rhythms with age. ${ }^{10}$ Drosophila which overexpress $A \beta$ peptides 
also show a severely disturbed circadian function, though their central pacemaker appears intact, suggesting a downstream effect of $A \beta$ that has not been defined. ${ }^{63,64}$ However, several studies in humans have suggested that dysfunction and degeneration of the SCN lies at the root of the circadian dysfunction in $\mathrm{AD} .{ }^{65-68}$ Pathological studies in humans reveal a significant loss of critical vasopressin- and vasoactive intestinal peptide-expressing neurons in the $\mathrm{SCN}$ in $\mathrm{AD}$, two neuronal populations that are known to maintain the SCN circadian function in mice. ${ }^{66,67}$ On a molecular level, expression of Bmal1 and Clock decline in senescent cells ${ }^{69}$ as well as in aged rodent brain tissues. ${ }^{70}$ Although impaired circadian rhythms have long been understood as a consequence of $\mathrm{AD}$, several lines of recent evidence suggest a possible causative role for circadian dysfunction in $\mathrm{AD}$ pathogenesis. Epidemiological data show that impaired systemic circadian rhythms in cognitively normal adults, as assessed by actigraphy, are a significant risk factor for the future development of $\mathrm{AD}^{71} \mathrm{In}$ this study, actigraphy data was analyzed for circadian parameters rather than sleep parameters, even though the primary data collection method was no different than that used in many studies examining sleep in AD. From a genetic standpoint, three small studies have identified three separate polymorphisms in the Clock gene that have been associated with an increased risk of $\mathrm{AD},{ }^{72-74}$ though these studies have not yet been replicated in larger cohorts. Finally, the previously described diurnal oscillations in $A \beta$ could be considered to have a circadian rhythm and could be mediated by upstream influences of the circadian system, ${ }^{25,26}$ though this has not yet been determined.

\section{Circadian clock gene deletion causes neuronal injury}

Although a little is known about the effect of the circadian clock on $A \beta$ or tau pathology in mammals, recent data from our group demonstrate that disruption of the core circadian clock in the brain might directly facilitate neurodegeneration. We generated mice with a brain-specific deletion of the master clock gene Bmal1 in the cortex and hippocampus but with the SCN spared, thus leaving systemic circadian rhythms and sleep-wake cycle intact in the animal while completely disrupting circadian transcriptional regulation in the rest of the brain. ${ }^{75}$ Despite normal behavioral rhythms (as assessed by wheel-running actigraphy) and sleep-wake cycle (as assessed by EEG), brain-specific Bmal1 knockout mice developed severe cortical astrogliosis, oxidative damage, and synaptic degeneration. This was associated with impaired circadian transcription of several redox defense genes. ${ }^{75}$ Decreasing levels of BMAL1 in the brain also exacerbated neurodegeneration caused by the mitochondrial toxin 3-nitropropionic acid. These data suggest that declines in circadian function, as seen in aging or $\mathrm{AD}$, might exacerbate neurodegeneration via decreased BMAL1mediated transcription. Further studies are needed to examine the regulation of clock genes in $\mathrm{AD}$, the downstream mechanisms mediated by the circadian clock in neurons and glia, and how circadian dysfunction regulates $\mathrm{A} \beta$, tau, and other $\mathrm{AD}$ related pathways.

\section{Summary, part II}

Although the investigation of the role of circadian rhythms and clock genes in $\mathrm{AD}$ pathogenesis is in its infancy, both human and animal data suggest that circadian dysfunction occurs in $\mathrm{AD}$ and may precede symptom onset. Furthermore, the circadian clock may have a key role in regulating the expression of neuroprotective proteins and preventing cerebral oxidative stress and synaptic damage (Figure 1). As a key regulator of the sleep-wake cycle, the circadian clock could also potentially contribute to the regulation of $A \beta$, though this remains to be seen. As the roles of clock genes in other diseases continue to be elucidated, further inquiry into the function of the circadian clock in both the healthy and diseased brain may yield important insights into $\mathrm{AD}$ pathogenesis.

\section{PART III: THERAPEUTIC IMPLICATIONS}

Therapies aimed at improving sleep quality and normalizing rhythms in sleep and behavior would address both the sleep and circadian systems and are thus particularly attractive. Considering the profound protective effect of almorexant on $\mathrm{A} \beta$ plaque burden in mice, ${ }^{25}$ the orexin system is a highpriority target. The recent approval of Suvorexant, the first Food and Drug Administration approved orexin receptor antagonist, provides an excellent opportunity to evaluate orexin-targeted therapeutics on $A \beta$ dynamics and cognitive endpoints in early-stage or presymptomatic $\mathrm{AD}$.

Melatonin and light therapy are two methods of synchronizing the circadian clock and enforcing a consistent diurnal rhythm of sleep and activity, and they have been studied extensively in aging and $\mathrm{AD}$ with mixed results. In addition to helping regulate circadian rhythms, melatonin is a versatile endogenous antioxidant, ${ }^{76}$ and its levels decrease both with age ${ }^{77}$ and preclinical AD. ${ }^{78}$ Regular melatonin supplementation may be slightly beneficial in improving cognitive performance of patients with mild cognitive impairment. ${ }^{79}$ In mice, however, there seems to be mixed data on the efficacy of melatonin supplementation on the reduction of amyloid plaques and other correlates of AD. ${ }^{80-83}$

Studies have suggested that melatonin has mixed effects in restoring diurnal rhythm in $\mathrm{AD}$ patients. Administration of melatonin at bedtime simulates the body's natural signal that it is night and exerts direct effects on clock gene expression in the SCN and other tissues. While studies in normal aged individuals suggest improvements in sleep quality with melatonin supplementation, ${ }^{84}$ studies have shown little, if any, effect on sleep in $\mathrm{AD}$ patients, ${ }^{85,86}$ suggesting additional factors other than endogenous melatonin levels may be affected by $\mathrm{AD}$ pathology.

Similarly, ensuring darkness at night and then applying highintensity white or blue light in the morning has similar effects on the circadian system. Studies have shown that bright-light therapy is effective in improving the stability of diurnal rhythms in dementia patients, ${ }^{87}$ although this therapy alone may not improve rhythms in AD patients. ${ }^{88}$ However, brightlight therapy in conjunction with melatonin appears more 
effective than either therapy alone. ${ }^{88,89}$ A specific melatonin M1/M2 receptor agonist (ramelteon) has been approved for insomnia, whereas a second M1/M2 selective receptor agonist (tasimelteon) has been approved for the treatment of circadian disturbance (termed non-24 h sleep-wake disorder) in the blind. Although neither of these agents has been tested in an $\mathrm{AD}$ setting, they may achieve higher potency than melatonin itself.

Although still in preclinical development, several groups are designing agents that directly target the circadian clock itself. High throughput screening has identified small molecules that can alter the expression of clock genes and change the amplitude, frequency, and period of circadian oscillations. ${ }^{90,91}$ Small molecule agonists of the orphan nuclear receptors RevErb $\alpha$ and $-\beta$, which are components of the extended circadian clock, can also exert direct effects on circadian rhythms in mice, leading to improvements in metabolic function. ${ }^{92}$ Thus, direct targeting of the circadian clock might provide a unique therapeutic opportunity for the treatment of neurodegenerative diseases in the future.

\section{CONCLUSION}

While improving sleep quality and circadian timing could have immediate positive effects on quality of life for $\mathrm{AD}$ patients and their caregivers, optimizing these parameters earlier in life might also provide a means of preventing or delaying the development of AD. Understanding the mechanisms by which sleep and circadian disturbances influence the disease process in $\mathrm{AD}$ may identify more specific therapeutic targets that could be engaged in healthy middle-aged individuals. Sleep and circadian function could thus represent modifiable risk factors for the future development of $\mathrm{AD}$ that are both diagnostically and therapeutically accessible.

\section{CONFLICT OF INTEREST}

The authors declare no conflict of interest.

\section{ACKNOWLEDGEMENTS}

The authors received funding from NIH grants P01NS074969 (DMH), PO1-AG03991 (DMH), and K08NS079405 (ESM); the JPB Foundation (DMH), Cure Alzheimer's Fund (DMH), Alzheimer's Association grant NIRP-14-305476 (ESM), and Donor's Cure Foundation (ESM).

1 Ju YE, Lucey BP, Holtzman DM. Sleep and Alzheimer disease pathology-a bidirectional relationship. Nat Rev Neurol 2014; 10: 115-119.

2 Peter-Derex L, Yammine P, Bastuji H, Croisile B. Sleep and Alzheimer's disease. Sleep Med Rev 2015; 19C: 29-38.

3 Hatfield CF, Herbert J, van Someren EJ, Hodges JR, Hastings MH. Disrupted daily activity/rest cycles in relation to daily cortisol rhythms of home-dwelling patients with early Alzheimer's dementia. Brain 2004; 127: 1061-1074.

4 Prinz PN, Peskind ER, Vitaliano PP, Raskind MA, Eisdorfer C, Zemcuznikov $\mathrm{N}$ et al. Changes in the sleep and waking EEGs of nondemented and demented elderly subjects. J Am Geriatr Soc 1982; 30: 86-93.
5 Petit D, Gagnon JF, Fantini ML, Ferini-Strambi L, Montplaisir J. Sleep and quantitative EEG in neurodegenerative disorders. J Psychosom Res 2004; 56: 487-496.

6 Martin PR, Loewenstein RJ, Kaye WH, Ebert MH, Weingartner H, Gillin JC. Sleep EEG in Korsakoff's psychosis and Alzheimer's disease. Neurology 1986; 36: 411-414

7 Loewenstein RJ, Weingartner H, Gillin JC, Kaye W, Ebert M, Mendelson WB. Disturbances of sleep and cognitive functioning in patients with dementia. Neurobiol Aging 1982; 3: 371-377.

8 Roh JH, Huang Y, Bero AW, Kasten T, Stewart FR, Bateman RJ et al. Disruption of the sleep-wake cycle and diurnal fluctuation of beta-amyloid in mice with Alzheimer's disease pathology. Sci Trans/ Med 2012; 4: 150ra122.

9 Duncan MJ, Smith JT, Franklin KM, Beckett TL, Murphy MP St, Clair DK et al. Effects of aging and genotype on circadian rhythms, sleep, and clock gene expression in APPxPS1 knock-in mice, a model for Alzheimer's disease. Exp Neurol 2012; 236: 249-258.

10 Sterniczuk R, Dyck RH, Laferla FM, Antle MC. Characterization of the 3xTgAD mouse model of Alzheimer's disease: part 1. Circadian changes. Brain Res 2010; 1348: 139-148.

11 Jyoti A, Plano A, Riedel G, Platt B. EEG, activity, and sleep architecture in a transgenic AbetaPPswe/PSEN1A246E Alzheimer's disease mouse. J Alzheimers Dis 2010; 22: 873-887.

12 Platt B, Drever B, Koss D, Stoppelkamp S, Jyoti A, Plano A et al. Abnormal cognition, sleep, EEG and brain metabolism in a novel knockin Alzheimer mouse, PLB1. PLoS ONE 2011; 6: e27068.

13 Wisor JP, Edgar DM, Yesavage J, Ryan HS, McCormick CM, Lapustea N et al. Sleep and circadian abnormalities in a transgenic mouse model of Alzheimer's disease: a role for cholinergic transmission. Neuroscience 2005; 131: 375-385.

14 Zhang B, Veasey SC, Wood MA, Leng LZ, Kaminski C, Leight S et al. Impaired rapid eye movement sleep in the Tg2576 APP murine model of Alzheimer's disease with injury to pedunculopontine cholinergic neurons. Am J Pathol 2005; 167: 1361-1369.

15 Hahn EA, Wang HX, Andel R, Fratiglioni L. A change in sleep pattern may predict Alzheimer Disease. Am J Geriatr Psychiatry 2014; 22: 1262-1271.

16 Sterniczuk R, Theou O, Rusak B, Rockwood K. Sleep disturbance is associated with incident dementia and mortality. Curr Alzheimer Res 2013; 10: 767-775.

17 Potvin O, Lorrain D, Forget H, Dube M, Grenier S, Preville M et al. Sleep quality and 1-year incident cognitive impairment in community-dwelling older adults. Sleep 2012; 35: 491-499.

18 Ancoli-Israel S, Cole R, Alessi C, Chambers M, Moorcroft W, Pollak CP. The role of actigraphy in the study of sleep and circadian rhythms. Sleep 2003, 26: 342-392

19 Marino M, Li Y, Rueschman MN, Winkelman JW, Ellenbogen JM, Solet JM et al. Measuring sleep: accuracy, sensitivity, and specificity of wrist actigraphy compared to polysomnography. Sleep 2013; 36: $1747-1755$.

20 Lim AS, Yu L, Costa MD, Leurgans SE, Buchman AS, Bennett DA et al. Increased fragmentation of rest-activity patterns is associated with a characteristic pattern of cognitive impairment in older individuals. Sleep 2012; 35: 633-640B

21 Lim AS, Kowgier M, Yu L, Buchman AS, Bennett DA. Sleep fragmentation and the risk of incident Alzheimer's disease and cognitive decline in older persons. Sleep 2013; 36: 1027-1032.

22 Lim AS, Yu L, Kowgier M, Schneider JA, Buchman AS, Bennett DA. Modification of the relationship of the apolipoprotein E epsilon4 allele to the risk of Alzheimer disease and neurofibrillary tangle density by sleep. JAMA Neurol 2013; 70: 1544-1551.

$23 \mathrm{Ju}$ YE, McLeland JS, Toedebusch CD, Xiong C, Fagan AM, Duntley SP et al. Sleep quality and preclinical Alzheimer disease. JAMA Neurol 2013; 70 587-593.

24 Spira AP, Gamaldo AA, An Y, Wu MN, Simonsick EM, Bilgel M et al. Selfreported sleep and beta-amyloid deposition in community-dwelling older adults. JAMA Neurol 2013; 70: 1537-1543.

25 Kang JE, Lim MM, Bateman RJ, Lee JJ, Smyth LP, Cirrito JR et al. Amyloidbeta dynamics are regulated by orexin and the sleep-wake cycle. Science 2009; 326: 1005-1007.

26 Huang Y, Potter R, Sigurdson W, Santacruz A, Shih S, Ju YE et al. Effects of age and amyloid deposition on Abeta dynamics in the human central nervous system. Arch Neurol 2012; 69: 51-58.

27 Kamenetz F, Tomita T, Hsieh H, Seabrook G, Borchelt D, Iwatsubo T et al. APP processing and synaptic function. Neuron 2003; 37: 925-937. 
28 Cirrito JR, Yamada KA, Finn MB, Sloviter RS, Bales KR, May PC et al. Synaptic activity regulates interstitial fluid amyloid-beta levels in vivo. Neuron 2005; 48: 913-922.

29 Bero AW, Yan P, Roh JH, Cirrito JR, Stewart FR, Raichle ME et al. Neuronal activity regulates the regional vulnerability to amyloid-beta deposition. Nat Neurosci 2011; 14: 750-756.

30 Nir Y, Staba RJ, Andrillon T, Vyazovskiy VV, Cirelli C, Fried I et al. Regional slow waves and spindles in human sleep. Neuron 2011; 70: 153-169.

31 Xie L, Kang H, Xu Q, Chen MJ, Liao Y, Thiyagarajan M et al. Sleep drives metabolite clearance from the adult brain. Science 2013; 342: 373-377.

32 Rothman SM, Herdener N, Frankola KA, Mughal MR, Mattson MP. Chronic mild sleep restriction accentuates contextual memory impairments, and accumulations of cortical Abeta and pTau in a mouse model of Alzheimer's disease. Brain Res 2013; 1529: 200-208.

33 Green KN, Billings LM, Roozendaal B, McGaugh JL, LaFerla FM. Glucocorticoids increase amyloid-beta and tau pathology in a mouse model of Alzheimer's disease. J Neurosci 2006; 26: 9047-9056.

34 Kang JE, Cirrito JR, Dong H, Csernansky JG, Holtzman DM. Acute stress increases interstitial fluid amyloid-beta via corticotropin-releasing factor and neuronal activity. Proc Natl Acad Sci USA 2007; 104: 10673-10678.

35 Dong H, Yuede CM, Yoo HS, Martin MV, Deal C, Mace AG et al. Corticosterone and related receptor expression are associated with increased beta-amyloid plaques in isolated Tg2576 mice. Neuroscience 2008; 155: 154-163.

36 Rothman SM, Herdener N, Camandola S, Texel SJ, Mughal MR, Cong WN et al. 3xTgAD mice exhibit altered behavior and elevated Abeta after chronic mild social stress. Neurobiol Aging 2012; 33: 830 e831-812.

37 Ooms S, Overeem S, Besse K, Rikkert MO, Verbeek M, Claassen JA. Effect of 1 night of total sleep deprivation on cerebrospinal fluid beta-Amyloid 42 in healthy middle-aged men: a randomized clinical trial. JAMA Neurol 2014; 71: 971-977.

38 Di Meco A, Joshi YB, Pratico D. Sleep deprivation impairs memory, tau metabolism, and synaptic integrity of a mouse model of Alzheimer's disease with plaques and tangles. Neurobiol Aging 2014; 35: 1813-1820.

39 Benedict C, Cedernaes J, Giedraitis V, Nilsson EK, Hogenkamp PS, Vagesjo $\mathrm{E}$ et al. Acute sleep deprivation increases serum levels of neuron-specific enolase (NSE) and S100 calcium binding protein B (S-100B) in healthy young men. Sleep 2014; 37: 195-198.

40 Zhang J, Zhu Y, Zhan G, Fenik P, Panossian L, Wang MM et al. Extended wakefulness: compromised metabolics in and degeneration of locus ceruleus neurons. J Neurosci 2014; 34: 4418-4431.

41 Naidoo N, Ferber M, Master M, Zhu Y, Pack Al. Aging impairs the unfolded protein response to sleep deprivation and leads to proapoptotic signaling. J Neurosci 2008; 28: 6539-6548.

42 Naidoo N, Giang W, Galante RJ, Pack Al. Sleep deprivation induces the unfolded protein response in mouse cerebral cortex. J Neurochem 2005; 92: 1150-1157.

43 Yan P, Bero AW, Cirrito JR, Xiao Q, Hu X, Wang Y et al. Characterizing the appearance and growth of amyloid plaques in APP/PS1 mice. $J$ Neurosci 2009; 29: 10706-10714.

44 Weaver DR. The suprachiasmatic nucleus: a 25-year retrospective. J Biol Rhythms 1998; 13: 100-112.

45 Mohawk JA, Green CB, Takahashi JS. Central and peripheral circadian clocks in mammals. Annu Rev Neurosci 2012; 35: 445-462.

46 Abe M, Herzog ED, Yamazaki S, Straume M, Tei H, Sakaki Y et al. Circadian rhythms in isolated brain regions. J Neurosci 2002; 22: 350-356.

47 Marpegan L, Swanstrom AE, Chung K, Simon T, Haydon PG, Khan SK et al. Circadian regulation of ATP release in astrocytes. J Neurosci 2011; 31: 8342-8350

48 Ptitsyn AA, Zvonic S, Conrad SA, Scott LK, Mynatt RL, Gimble JM. Circadian clocks are resounding in peripheral tissues. PLoS Comput Biol 2006; 2: e16.

49 Husse J, Leliavski A, Tsang AH, Oster H, Eichele G. The light-dark cycle controls peripheral rhythmicity in mice with a genetically ablated suprachiasmatic nucleus clock. FASEB J 2014; 28: 4950-4960.

50 Kondratov RV, Antoch MP. The clock proteins, aging, and tumorigenesis. Cold Spring Harb Symp Quant Biol 2007; 72: 477-482.

51 Anea CB, Zhang M, Stepp DW, Simkins GB, Reed G, Fulton DJ et al. Vascular disease in mice with a dysfunctional circadian clock. Circulation 2009; 119: 1510-1517.

52 Bass J, Takahashi JS. Circadian integration of metabolism and energetics. Science 2010; 330: 1349-1354.
53 Evans JA, Davidson AJ. Health consequences of circadian disruption in humans and animal models. Prog Mol Biol Transl Sci 2013; 119: 283-323.

54 Bunger MK, Wilsbacher LD, Moran SM, Clendenin C, Radcliffe LA, Hogenesch JB et al. Mop3 is an essential component of the master circadian pacemaker in mammals. Cell 2000; 103: 1009-1017.

55 Laposky A, Easton A, Dugovic C, Walisser J, Bradfield C, Turek F. Deletion of the mammalian circadian clock gene BMAL1/Mop3 alters baseline sleep architecture and the response to sleep deprivation. Sleep 2005; 28 : 395-409.

56 Mongrain V, La Spada F, Curie T, Franken P. Sleep loss reduces the DNAbinding of BMAL1, CLOCK, and NPAS2 to specific clock genes in the mouse cerebral cortex. PLOS ONE 2011; 6: e26622.

57 Chang HC, Guarente L. SIRT1 mediates central circadian control in the SCN by a mechanism that decays with aging. Cell 2013; 153 . $1448-1460$.

58 Witting W, Kwa IH, Eikelenboom P, Mirmiran M, Swaab DF. Alterations in the circadian rest-activity rhythm in aging and Alzheimer's disease. Biol Psychiatry 1990; 27: 563-572.

59 Coogan AN, Schutova B, Husung S, Furczyk K, Baune BT, Kropp P et al. The circadian system in Alzheimer's disease: disturbances, mechanisms, and opportunities. Biol Psychiatry 2013; 74: 333-339.

$60 \mathrm{Hu}$ K, Van Someren EJ, Shea SA, Scheer FA. Reduction of scale invariance of activity fluctuations with aging and Alzheimer's disease: involvement of the circadian pacemaker. Proc NatI Acad Sci USA 2009; 106: 2490-2494.

$61 \mathrm{Wu}$ YH, Fischer DF, Kalsbeek A, Garidou-Boof ML, van der Vliet J, van Heijningen $\mathrm{C}$ et al. Pineal clock gene oscillation is disturbed in Alzheimer's disease, due to functional disconnection from the "master clock". FASEB J 2006; 20: 1874-1876.

62 Skene DJ, Swaab DF. Melatonin rhythmicity: effect of age and Alzheimer's disease. Exp Gerontol 2003; 38: 199-206.

63 Chen KF, Possidente B, Lomas DA, Crowther DC. The central molecular clock is robust in the face of behavioural arrhythmia in a Drosophila model of Alzheimer's disease. Dis Model Mech 2014; 7: 445-458.

64 Long DM, Blake MR, Dutta S, Holbrook SD, Kotwica-Rolinska J, Kretzschmar $\mathrm{D}$ et al. Relationships between the Circadian system and Alzheimer's disease-like symptoms in Drosophila. PLOS ONE 2014; 9: e106068.

65 Harper DG, Stopa EG, Kuo-Leblanc V, McKee AC, Asayama K, Volicer L et al. Dorsomedial SCN neuronal subpopulations subserve different functions in human dementia. Brain 2008; 131: 1609-1617.

66 Swaab DF, Fliers E, Partiman TS. The suprachiasmatic nucleus of the human brain in relation to sex, age and senile dementia. Brain Res 1985; 342: $37-44$

67 Zhou JN, Hofman MA, Swaab DF. VIP neurons in the human SCN in relation to sex, age, and Alzheimer's disease. Neurobiol Aging 1995; 16 : 571-576.

68 Farajnia S, Michel S, Deboer T, Vanderleest HT, Houben T, Rohling JH et al. Evidence for neuronal desynchrony in the aged suprachiasmatic nucleus clock. J Neurosci 2012; 32: 5891-5899.

69 Kunieda T, Minamino T, Katsuno T, Tateno K, Nishi J, Miyauchi $\mathrm{H}$ et al. Cellular senescence impairs circadian expression of clock genes in vitro and in vivo. Circ Res 2006; 98: 532-539.

70 Wyse CA, Coogan AN. Impact of aging on diurnal expression patterns of CLOCK and BMAL1 in the mouse brain. Brain Res 2010; 1337: 21-31.

71 Tranah GJ, Blackwell T, Stone KL, Ancoli-Israel S, Paudel ML, Ensrud KE et al. Circadian activity rhythms and risk of incident dementia and mild cognitive impairment in older women. Ann Neurol 2011; 70: 722-732.

72 Chen HF, Huang CQ, You C, Wang ZR, Si-qing H. Polymorphism of CLOCK gene rs $4580704 \mathrm{C}>\mathrm{G}$ is associated with susceptibility of Alzheimer's disease in a Chinese population. Arch Med Res 2013; 44: 203-207.

73 Chen Q, Huang CQ, Hu XY, Li SB, Zhang XM. Functional CLOCK gene rs1554483 G/C polymorphism is associated with susceptibility to Alzheimer's disease in the Chinese population. J Int Med Res 2013; 41: 340-346.

74 Yang YK, Peng XD, Li YH, Wang ZR, Chang-quan H, Hui W et al. The polymorphism of CLOCK gene $3111 \mathrm{~T} / \mathrm{C} C>\mathrm{T}$ is associated with susceptibility of Alzheimer disease in Chinese population. J Investig Med 2013; 61: 1084-1087.

75 Musiek ES, Lim MM, Yang G, Bauer AQ, Qi L, Lee Y et al. Circadian clock proteins regulate neuronal redox homeostasis and neurodegeneration. J Clin Invest 2013; 123: 5389-5400.

76 Galano A, Tan DX, Reiter RJ. Melatonin as a natural ally against oxidative stress: a physicochemical examination. J Pineal Res 2011; 51: 1-16. 
77 Rosales-Corral SA, Acuna-Castroviejo D, Coto-Montes A, Boga JA, Manche ster LC, Fuentes-Broto $L$ et al. Alzheimer's disease: pathological mechanisms and the beneficial role of melatonin. J Pineal Res 2012; 52: 167-202.

78 Zhou JN, Liu RY, Kamphorst W, Hofman MA, Swaab DF. Early neuropathological Alzheimer's changes in aged individuals are accompanied by decreased cerebrospinal fluid melatonin levels. J Pineal Res 2003; 35: $125-130$.

79 Furio AM, Brusco LI, Cardinali DP. Possible therapeutic value of melatonin in mild cognitive impairment: a retrospective study. J Pineal Res 2007; 43: 404-409.

80 Quinn J, Kulhanek D, Nowlin J, Jones R, Pratico D, Rokach J et al. Chronic melatonin therapy fails to alter amyloid burden or oxidative damage in old Tg2576 mice: implications for clinical trials. Brain Res 2005; 1037: 209-213.

81 Olcese JM, Cao C, Mori T, Mamcarz MB, Maxwell A, Runfeldt MJ et al. Protection against cognitive deficits and markers of neurodegeneration by long-term oral administration of melatonin in a transgenic model of Alzheimer disease. J Pineal Res 2009; 47: 82-96.

82 Feng Z, Qin C, Chang Y, Zhang JT. Early melatonin supplementation alleviates oxidative stress in a transgenic mouse model of Alzheimer's disease. Free Radic Biol Med 2006; 40: 101-109.

83 Garcia-Mesa Y, Gimenez-Llort L, Lopez LC, Venegas C, Cristofol R, Escames $\mathrm{G}$ et al. Melatonin plus physical exercise are highly neuroprotective in the 3xTg-AD mouse. Neurobiol Aging 2012; 33: 1124 e1113-1129.

84 Brzezinski A, Vangel MG, Wurtman RJ, Norrie G, Zhdanova I, Ben-Shushan A et al. Effects of exogenous melatonin on sleep: a meta-analysis. Sleep Med Rev 2005; 9: 41-50.

85 Gehrman PR, Connor DJ, Martin JL, Shochat T, Corey-Bloom J, AncoliIsrael S. Melatonin fails to improve sleep or agitation in double-blind randomized placebo-controlled trial of institutionalized patients with Alzheimer disease. Am J Geriatr Psychiatry 2009; 17: 166-169.

86 Singer C, Tractenberg RE, Kaye J, Schafer K, Gamst A, Grundman M et al. A multicenter, placebo-controlled trial of melatonin for sleep disturbance in Alzheimer's disease. Sleep 2003; 26: 893-901.
87 Van Someren EJ, Kessler A, Mirmiran M, Swaab DF. Indirect bright light improves circadian rest-activity rhythm disturbances in demented patients. Biol Psychiatry 1997; 41: 955-963.

88 Dowling GA, Burr RL, Van Someren EJ, Hubbard EM, Luxenberg JS, Mastick J et al. Melatonin and bright-light treatment for rest-activity disruption in institutionalized patients with Alzheimer's disease. J Am Geriatr Soc 2008; 56: 239-246.

89 Riemersma-van der Lek RF, Swaab DF, Twisk J, Hol EM, Hoogendijk WJ, Van Someren EJ. Effect of bright light and melatonin on cognitive and noncognitive function in elderly residents of group care facilities: a randomized controlled trial. JAMA 2008; 299: 2642-2655.

90 Hirota T, Lee JW, Lewis WG, Zhang EE, Breton G, Liu X et al. Highthroughput chemical screen identifies a novel potent modulator of cellular circadian rhythms and reveals CKIalpha as a clock regulatory kinase. PLoS Biol 2010; 8: e1000559.

91 Chen Z, Yoo SH, Park YS, Kim KH, Wei S, Buhr E et al. Identification of diverse modulators of central and peripheral circadian clocks by highthroughput chemical screening. Proc NatI Acad Sci USA 2012; 109 101-106.

92 Solt LA, Wang Y, Banerjee S, Hughes T, Kojetin DJ, Lundasen T et al. Regulation of circadian behaviour and metabolism by synthetic REV-ERB agonists. Nature 2012; 485: 62-68.

$(1) \circledast \ominus$ This work is licensed under a Creative Commons Attribution-NonCommercial-NoDerivs 3.0 Unported License. The images or other third party material in this article are included in the article's Creative Commons license, unless indicated otherwise in the credit line; if the material is not included under the Creative Commons license, users will need to obtain permission from the license holder to reproduce the material. To view a copy of this license, visit http://creativecommons.org/licenses/by-nc-nd/3.0/ 